University of South Florida

DIGITAL COMMONS

Digital Commons @ University of

@ UNIVERSITY OF SOUTH FLORIDA

South Florida

8-2003

\title{
A Cloud-Free, Satellite-Derived, Sea Surface Temperature Analysis for the West Florida Shelf
}

\author{
Ruoying $\mathrm{He}$ \\ University of South Florida \\ Robert $\mathrm{H}$. Weisberg \\ University of South Florida, weisberg@marine.usf.edu \\ Haiying Zhang \\ University of South Florida \\ Frank E. Muller-Karger \\ University of South Florida, carib@marine.usf.edu \\ Robert W. Helber \\ University of South Florida
}

Follow this and additional works at: https://digitalcommons.usf.edu/msc_facpub

\section{Scholar Commons Citation}

He, Ruoying; Weisberg, Robert H.; Zhang, Haiying; Muller-Karger, Frank E.; and Helber, Robert W., "A CloudFree, Satellite-Derived, Sea Surface Temperature Analysis for the West Florida Shelf" (2003). Marine Science Faculty Publications. 363.

https://digitalcommons.usf.edu/msc_facpub/363

This Article is brought to you for free and open access by the College of Marine Science at Digital Commons @ University of South Florida. It has been accepted for inclusion in Marine Science Faculty Publications by an authorized administrator of Digital Commons @ University of South Florida. For more information, please contact digitalcommons@usf.edu. 


\title{
A cloud-free, satellite-derived, sea surface temperature analysis for the West Florida Shelf
}

\author{
Ruoying He, Robert H. Weisberg, Haiying Zhang, Frank E. Muller-Karger, \\ and Robert W. Helber \\ College of Marine Science, University of South Florida, St. Petersburg, Florida, USA
}

Received 2 May 2003; accepted 8 July 2003; published 9 August 2003.

[1] Clouds are problematic in using Advanced Very High Resolution Radiometer (AVHRR) imagery for describing sea surface temperature (SST). The Tropical Rainfall Measuring Mission Microwave Imager (TMI) observes SST through clouds, providing daily, $1 / 4^{\circ}$ maps under all weather conditions excepting rain. A TMI limitation, however, is coarse resolution. Optimal interpolation (OI) is used to generate a cloud-free, $5-\mathrm{km}$, daily SST analysis for the West Florida Shelf (WFS) by merging the high-resolution (cloudcovered) AVHRR with the coarse-resolution (cloud-free) TMI SST products. Comparisons with in-situ data show good agreements. Given large spatial gradients by coastal ocean processes, this regional analysis has advantage over the global, weekly, $1^{\circ}$ Reynolds SST. A 5-year (1998-2002) OI SST analysis is diagnosed using Empirical Orthogonal Functions. The first two modes represent annual cycles, one by surface heat flux and another by shelf circulation dynamics. INDEX TERMS: 4219 Oceanography: General: Continental shelf processes; 4275 Oceanography: General: Remote sensing and electromagnetic processes (0689); 4227 Oceanography: General: Diurnal, seasonal, and annual cycles. Citation: He, R., R. H. Weisberg, H. Zhang, F. E. Muller-Karger, and R. W. Helber, A cloud-free, satellite-derived, sea surface temperature analysis for the West Florida Shelf, Geophys. Res. Lett., 30(15), 1811, doi:10.1029/2003GL017673, 2003.

\section{Introduction}

[2] The West Florida Shelf (WFS) is a broad, gently sloping continental margin (Figure 1) with highly variable ecosystems. Driven by local momentum and buoyancy forcing, and influenced by the offshore Loop Current, the shelf circulation determines the transport of nutrients and hence affects both primary and secondary production. The shelf circulation is dynamically linked to other varying water properties, and particularly to temperature, which exerts a primary control on density. Recent studies [He and Weisberg, 2002, 2003; Weisberg and He, 2003; MullerKarger, 2000] show how the shelf water temperature variability is related to variability in net surface heat flux and ocean advection. However, a limitation to previous descriptive and modeling studies has been the intermittency of satellite sea surface temperature (SST) maps because of cloud contamination [Muller-Karger, 2000; Muller-Karger et al., 1991]. The present paper presents an improved, high resolution, cloud-free SST analysis for the WFS.

[3] We begin in section 2 with a description of the satellite data to be used. Section 3 outlines the optimal interpolation

Copyright 2003 by the American Geophysical Union. 0094-8276/03/2003GL017673
(OI) procedure for generating an OI SST analysis by combining Advanced Very High Resolution Radiometer (AVHRR) SST with Tropical Rainfall Measuring Mission (TRMM) Microwave Imager (TMI) SST. With a 5-year OI SST analysis, Empirical Orthogonal Functions (EOFs) are employed in Section 4 to describe the WFS SST variability in time and space. Section 5 summarizes the results.

\section{Data}

[4] Two satellite-derived SST products are available for the WFS. The first consists of AVHRR images from the National Oceanic and Atmospheric Administration Polar Orbiting Environmental Satellites (NOAA-POES). Its advantage is high spatial resolution $(\sim 1 \mathrm{~km})$ with several images per day. Its disadvantage is cloud contamination, which renders many of these images unusable, often for days at a time (the longest cloud-cover periods for the WFS generally happen in summer and fall during hurricane/tropical storm events when the clouds usually linger around several days). The second consists of TMI images from the National Aeronautics and Space Administration (NASA) TRMM satellite launched in November 1997. It has the advantage of being cloud-free, with generally two images per day exclusive of rain [Wentz et al., 2000], but it suffers the disadvantages of coarse resolution $\left(1 / 4^{\circ}\right)$ and a near-land mask of some $50 \mathrm{~km}$. Our goal is to construct a multiyear time series of gridded, satellite-derived SST by combining the attributes of both data sets. In this way we seek an unbiased and continuous daily SST product that can be used for oceanographic analyses and as boundary conditions for numerical circulation models.

[5] The AVHRR data are collected using a High Resolution Picture Transmission (HRPT) antenna located at the University of South Florida, St. Petersburg, FL http://imars. usf.edu). All nighttime and daytime passes from all satellites (the NOAA 11 through 17 satellites) are archived, and SST is computed using the multichannel sea-surface temperature (MCSST) algorithm developed by McClain et al. [1985]. The TMI data, with images generally available twice per day, are obtained from Remote Sensing System http:// www.ssmi.com). The root mean square (rms) errors for both the AVHRR [McClain et al., 1983; Strong and McClain, 1984; Walton, 1988; Wick et al., 1992] and the TMI [Wentz and Meissner, 2000] SST products are approximately $0.6^{\circ} \mathrm{C}$.

\section{Optimal Interpolation}

[6] The AVHRR and TMI SST products are merged through an optimal interpolation (OI) method to generate a cloud-free, gridded, high-resolution $(5 \mathrm{~km})$, daily SST 


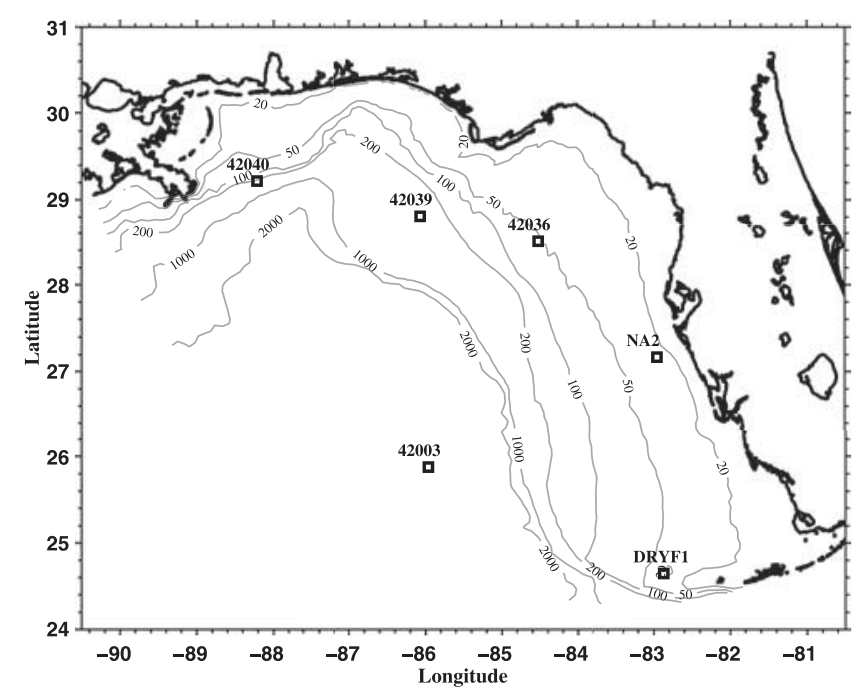

Figure 1. The locations of the National Data Buoy Center (NDBC) and the University of South Florida buoys used in this study.

analysis for the WFS for the 5-year period 1998-2002. Quality control and data reduction procedures are performed prior to the OI analysis. First, observations are discarded if the SST value lies outside an error radius of two climatological standard deviations for a given month [Casey and Cornillon, 1999]. Next, for either TMI or AVHRR, each daily ensemble of daytime and nighttime observations are averaged. For computational reasons, the number of observation are further reduced by averaging into $5 \mathrm{~km}$ boxes since the correlation matrices used in OI may become singular if observations are spaced at much smaller distances [Reynolds and Smith, 1994].

[7] The OI merging procedure is based on Carter and Robison [1987] with a modification to the correlation model to reduce the amount of smoothing. The analysis is determined relative to the monthly ensemble-mean of all satellite observations, which is used as the first guess field. The value of the estimated field at a specific time and grid location is then determined by

$$
T_{j}^{O I}=\sum_{k=1}^{N} B_{j k}\left[\sum_{i=1}^{N} A_{k i}^{-1} T_{i}^{O B S}\right]
$$

where $T_{j}^{O I}$ is the estimated value relative to the first guess at $\left(x_{j}, y_{j}, t_{j}\right), T_{i}^{O B S}$ is an observation relative to the first guess at $\left(x_{i}, y_{i}, t_{i}\right), A$ is the correlation matrix between the observations, $B$ is the correlation matrix between the estimations and observations, and $N$ is the total number of observations. For either $A$ or $B$, each element in the matrix is a function of separation in time and space and can be calculated as:

$$
\begin{aligned}
& A_{k i}= \exp \left(-a b s\left(t_{k}-t_{i}\right) / t_{d}\right) \\
& \cdot \exp \left(-\left(\left(x_{k}-x_{i}\right) / x_{d}\right)^{2}-\left(\left(y_{k}-y_{i}\right) / y_{d}\right)^{2}\right)+\varepsilon^{2} \delta_{k i} \\
& B_{j k}= \exp \left(-a b s\left(t_{j}-t_{k}\right) / t_{d}\right) \\
& \cdot \exp \left(-\left(\left(x_{j}-x_{k}\right) / x_{d}\right)^{2}-\left(\left(y_{j}-y_{k}\right) / y_{d}\right)^{2}\right) \\
& k=1, \ldots, N ; \quad i=1, \ldots, N ; \\
& \delta_{k i}=1, \quad \text { if } \quad k=i ; \quad \delta_{k i}=0, \quad \text { if } k \neq i
\end{aligned}
$$

where $\varepsilon^{2}$ is the observational error variance (assumed to be homogeneous and with errors independent from point to point), and, $t_{d}, x_{d}$, and $y_{d}$ are temporal and spatial correlation scales. We use $t_{d}=2$ days, $x_{d}=y_{d}=30 \mathrm{~km}$ (approximately corresponding to the baroclinic Rossby radius of deformation at the local shelf break), and $\varepsilon^{2}=0.1$. In this way observations that are made over several days within a given area are merged into a single, daily field of $5 \mathrm{~km}$ resolution, for which all data are weighted by their distances in time and space. Daily cloud-free images may thus be obtained since enough data exist in time and space to interpolate over cloudcontaminated regions. The analysis is completed by adding the OI estimation to the first guess at each grid point.

[8] Similar OI methods have been applied to AVHRR SST alone for both global [e.g., Reynolds and Smith, 1994] and regional [e.g., Bisagni et al., 2001] analyses. The Reynolds and Smith [1994] analysis uses OI to merge AVHRR SST with in-situ data to produce weekly, $1^{\circ} \times 1^{\circ}$ SST maps that are useful for describing global scale temperature patterns. However, they are unable to resolve the WFS SST variability that takes place over much finer temporal and spatial scales. The Bisagni et al. [2001] analysis uses AVHRR SST for a 5-day, $7 \mathrm{~km}$ resolution product for the Gulf of Maine.

[9] We validate our 5-year (1998-2002), daily OI SST fields through direct comparisons with daily-averaged, insitu measured temperature from 6 buoys that span the WFS from the nearshore to the deep-ocean (Figure 1). The comparisons are made between the gridded analysis and the buoy observation within a given grid. The comparison statistics (Table 1) show that with the seasonal cycles retained in the analysis and the observation the correlation coefficients are all above 0.96 , the mean offsets are all less than $0.27^{\circ} \mathrm{C}$, and the RMS differences range between $0.58^{\circ} \mathrm{C}$ and $0.88^{\circ} \mathrm{C}$. When the seasonal cycles are removed from the analysis and the observation, the correlation coefficients at sub-seasonal scales range between 0.78 and 0.87 , and the RMS differences range between $0.5^{\circ} \mathrm{C}$ and $0.72^{\circ} \mathrm{C}$. These small differences between the OI satellitederived SST and the in-situ buoy-measured SST in either case, with or without the seasonal cycle, are due to a number of factors, including errors in the TMI and AVHRR retrievals (e.g., the performance degeneration of NOAA-14 in mid 2000), the spatial offsets between the buoy point measurements and the OI SST $5 \mathrm{~km}$ footprint, the difference between ocean skin temperature and the bulk upper ocean temperature measured 1 to $2 \mathrm{~m}$ below the surface by the buoys, daily ensemble averaging errors due to day-night

Table 1. Comparisons of OI SST With Co-located Buoy Observations

\begin{tabular}{lcccc}
\hline \multicolumn{1}{c}{$\begin{array}{c}\text { Buoy } \\
\text { number }\end{array}$} & $\begin{array}{c}\text { number of } \\
\text { observations }\end{array}$ & $\begin{array}{c}\text { mean } \\
\text { offsets }\end{array}$ & $\begin{array}{c}\text { Cycle retained/ } \\
\text { removed }\end{array}$ & $\begin{array}{c}\text { Seasonal } \\
\text { retained/ } \\
\text { removed }\end{array}$ \\
\hline 42040 & 1725 & $0.22^{\circ} \mathrm{C}$ & $0.67 / 0.61^{\circ} \mathrm{C}$ & $0.99 / 0.85$ \\
42039 & 1793 & $0.19^{\circ} \mathrm{C}$ & $0.68 / 0.63^{\circ} \mathrm{C}$ & $0.98 / 0.81$ \\
42036 & 1826 & $0.27^{\circ} \mathrm{C}$ & $0.58 / 0.50^{\circ} \mathrm{C}$ & $0.99 / 0.87$ \\
USF NA2 (42013) & 1015 & $-0.24^{\circ} \mathrm{C}$ & $0.88 / 0.72^{\circ} \mathrm{C}$ & $0.98 / 0.78$ \\
42003 & 1810 & $-0.19^{\circ} \mathrm{C}$ & $0.63 / 0.59^{\circ} \mathrm{C}$ & $0.96 / 0.79$ \\
DRYF1 & 1616 & $0.12^{\circ} \mathrm{C}$ & $0.68 / 0.62^{\circ} \mathrm{C}$ & $0.98 / 0.78$ \\
\hline
\end{tabular}

Provided are mean offsets, RMS errors, and correlation coefficients between the OI SST and the in-situ measured near-surface temperature. 

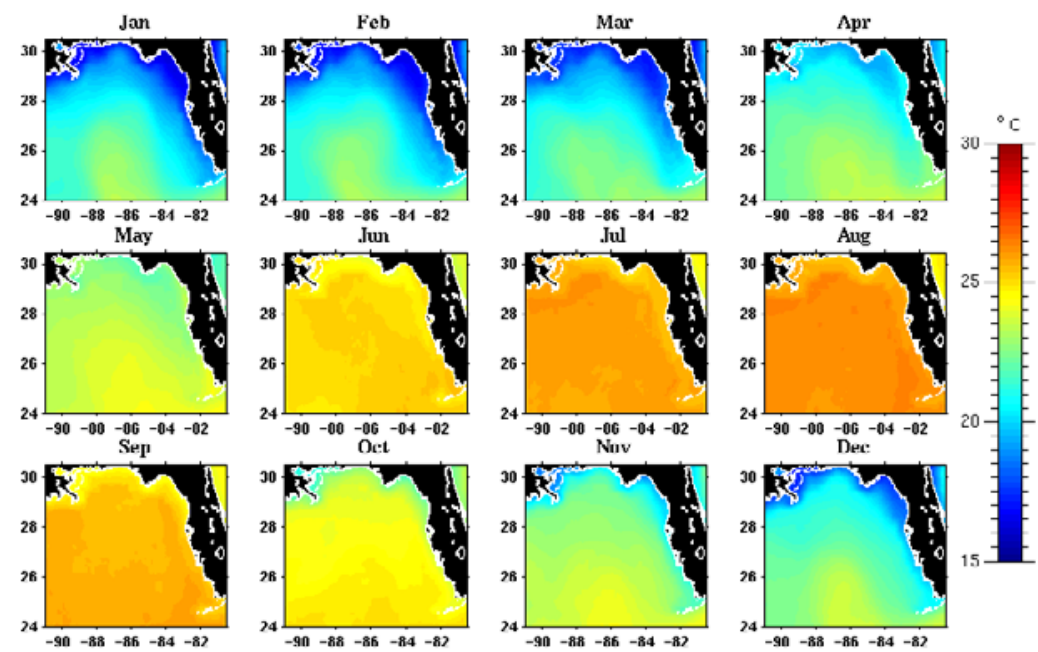

Figure 2. OI SST monthly means obtained by forming an average for each month over the 5-year period, $1998-2002$.

skin temperature differences, and the analysis errors inherent to the OI scheme. In view of these potential sources for error the comparison between the OI SST analysis and the in situ data are very good.

[10] As an example, Figure 2 shows the monthly mean OI SST fields, computed over the entire 5-year analysis period. WFS SST features documented in previous studies, such as warm Loop Current water seaward of the shelf break, and the spring cold tongue [Weisberg et al., 1996; He and Weisberg, 2002; Muller-Karger, 2000], which are missing in other coarse SST analyses (e.g., Reynold's $1^{\circ} \times 1^{\circ} \mathrm{SST}$ ), are all captured by this $5 \mathrm{~km}$ OI SST analysis. The entire analysis along with more detailed comparisons with the original AVHRR and TMI data sets are available online at http:// ocg6.marine.usf.edu.

\section{EOF Analysis}

[11] The gridded, cloud free OI SST fields allow us to investigate the temporal and spatial variability of WFS SST by decomposing these multidimensional fields into EOFs [such as performed with AVHRR SST for the Santa Barbara Channel by Lagerloef and Bernstein, 1988]. By organizing the OI SST fields in an $\mathrm{M} \times \mathrm{N}$ matrix, where $\mathrm{M}$ and $\mathrm{N}$ represent the spatial (27300 grid points) and the temporal (1832 days) elements, respectively, the SST matrix, $T(x, t)$, may be represented by

$$
T(x, t)=\sum_{n=1}^{N} a_{n}(t) F_{n}(x)
$$

where the $a_{n}$ are the temporal evolution functions and the $F_{n}$ are the spatial eigenfunctions for each EOF mode, respectively. Prior to the EOF analysis, temporal means are removed from the original OI SST fields using

$$
T^{\prime}(x, t)=T(x, t)-\frac{1}{N} \sum_{j=1}^{N} T\left(x, t_{j}\right)
$$

where $T^{\prime}(x, t)$ are the resulting residuals. The EOF analysis then provides temporal and spatial functions deriving from the $T^{\prime}(x, t)$ covariances. The results for the first $3 \mathrm{EOF}$ modes are shown in Figure 3. The color panels are the orthogonal spatial eigenfunctions that contain the temperature units, and the time series are their respective orthonormal temporal evolution functions.

[12] The first EOF mode accounts for $90.6 \%$ of the SST variance. With annual periodicity peaking in summer (September) and winter (February) this mode represents the seasonal surface heat flux cycle (and Muller-Karger et al., 1991, show a similar satellite observed annual cycle for the deep Gulf of Mexico). The first mode eigenfunction shows two different regimes, the wide WFS and the deep ocean. The WFS is colder in winter and warmer in summer than the adjacent deep-ocean. This is a consequence of water depth and the buffering effect on temperature by the warm water advection of the Gulf of Mexico Loop Current. Thus, the Loop Current presents the WFS with a cooling tendency in summer and a warming tendency in winter.

[13] The second EOF mode accounts for $3.5 \%$ of the SST variance. It also has annual periodicity, but with peaks in spring (March/May) and fall (October/December). The second mode eigenfunction reveals a tongue-like feature at mid-shelf emanating southward from Cape San Blas. It corresponds to the spring cold tongue (and fall warm tongue) features that arise due to the combined baroclinic and barotropic responses of the WFS circulation to the seasonal surface heat and momentum fluxes as described in previous studies [Weisberg et al., 1996; He and Weisberg, 2002]. We note that the temporal evolution function also shows significant inter-annual variability. Such inter-annual variability in the cross-shelf temperature gradients translates to similar variability in the baroclinic currents, and this results from inter-annual variability in both the local and deep-ocean forcing influences on the WFS [Weisberg and He, 2003]. Again as a demonstration of the utility of this high resolution OI SST product, we note that the tongue-like feature on the middle shelf is missing when applying the same EOF analysis to the coarse resolution Reynolds's $1^{\circ} \times 1^{\circ} \mathrm{SST}$ fields.

[14] The third EOF mode accounts for $0.9 \%$ of the SST variance. Its fluctuations occur at higher frequency than the first two modes. With the spatial pattern highlighting the nearshore and the Loop Current regions, this mode begins to 


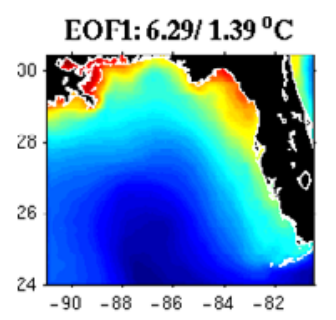

PC1: $90.59 \%$

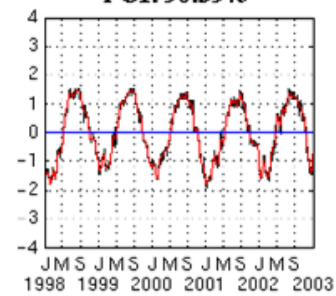

EOF2: $0.871-1.90^{\circ} \mathrm{C}$

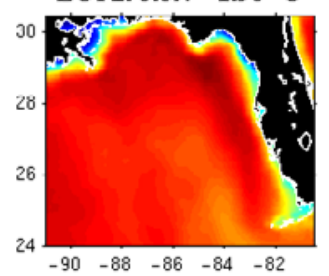

PC2: $3.47 \%$

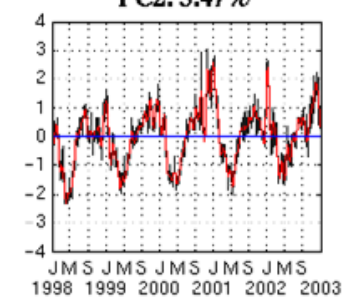

EOF3: $0.91 /-0.89^{\circ} \mathrm{C}$

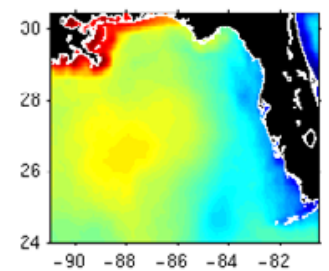

PC3: $0.88 \%$

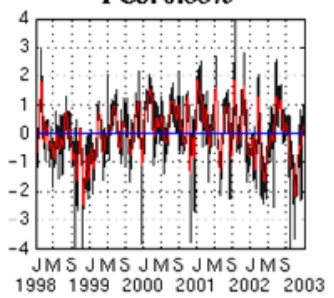

Figure 3. Eigenfunctions and temporal evolution functions for the first three-EOF modes. The numbers atop each eigenfunction are the maximum and minimum of each mode. The numbers atop each temporal evolution function are the percent of SST variance accounted for by each mode. 30-day low-pass filtered versions (red) are overlaid on the daily analyses (gray) for each mode.

describe the synoptic scale variability. However, with some $5 \%$ of the variance remaining in higher modes a reconstruction of the data set to account for the synoptic scales would require several more modes.

\section{Summary}

[15] We began with the premise that satellite SST maps provide important information on the continental shelf circulation and its related physical and biological processes. Two satellite SST products are available, each with advantages and disadvantages. AVHRR provides high spatialresolution, but is often contaminated by the clouds. TMI provides cloud-free images, but is limited by coarse spatial resolution and a large nearshore mask. An optimal interpolation (OI) method was therefore used to generate a daily, $5 \mathrm{~km}$ resolution, cloud-free SST analysis for the WFS by merging the AVHRR with the TMI images. Inter-comparisons between this 5-year (1998-2002) OI SST analysis and in-situ SST data from buoys moored across the WFS from the nearshore to the deep-ocean demonstrate the utility of the analysis for describing the temporal and spatial variability of WFS SST. As an application of the OI SST a further analysis was performed using EOFs. The first mode, accounting for $90.6 \%$ of the SST variance, represents the seasonal cycle in surface heat flux with peaks in summer and winter. The second mode, accounting for $3.5 \%$ of the SST variance, represents the seasonal cycle in across-shelf temperature gradients associated with the spring (fall) cold (warm) tongue resultant from the baroclinic and barotropic responses of the shelf circulation to seasonal surface heat and momentum fluxes. Inter-annual variability is also noted and attributed to inter-annual variations in both local and deep-ocean forcing influences on the WFS. The third mode, accounting for $0.9 \%$ of the SST variance, begins to represent the synoptic scale variability that occurs on the shelf and within the Loop Current.

[16] Along with the OI SST monthly means provided, interested readers may view the entire 5 -year, daily, $5 \mathrm{~km}$, cloud-free analysis, along with the original AVHRR and TMI images from which the analysis derives, online at http://ocg6.marine.usf.edu. Future applications of this high resolution OI SST analysis may include testing hypotheses on the interactions between physical and biological processes on the WFS, and constraining the net surface heat flux boundary condition for coastal ocean nowcast/forecast models.

[17] Acknowledgments. Support was provided by the Office of Naval Research, Grant \#s N00014-98-1-0158 and N00014-02-1-0972 to RHW and the National Aeronautics and Space Administration Grant \# NAG5-11254 to FMK. The AVHRR data for this region are collected, processed, and distributed by the University of South Florida (http:// imars.usf.edu). The TMI data are produced by Remote Sensing Systems and sponsored by NASA's Earth Science Information Partnerships (ESIP): a federation of information sites for Earth Science; and by NASA's TRMM Science Team. We are grateful to two anonymous reviewers who provided constructive and thoughtful comments and suggestions.

\section{References}

Bisagni, J. J., K. W. Seemann, and T. P. Mavor, High-resolution satellitederived sea-surface temperature variability over the Gulf of Maine and Georges Bank region, 1993-1996, Deep Sea Res., Part II, 48, 71-94, 2001.

Carter, E. F., and A. R. Robinson, Analysis models for the estimation of oceanic fields, J. Atmos. Oceanic Technol., 4, 49-74, 1987.

Casey, K. S., and P. Cornillon, A comparison of satellite and in-situ based sea surface temperature climatologies, J. Clim., 12, 1848-1863, 1999.

He, R., and R. H. Weisberg, West Florida Shelf circulation and temperature budget for the 1999 spring transition, Cont. Shelf Res., 22(5), 719-748, 2002.

He, R., and R. H. Weisberg, West Florida shelf circulation and temperature budget for the 1998 fall transition, Cont. Shelf Res., 23(8), 777-800, 2003.

Lagerloef, G. S. E., and R. L. Bernstein, Empirical orthogonal function analysis of advanced very High Resolution Radiometer surface temperature patterns in Santa Barbara Channel, J. Geophys. Res., 93, 68636873, 1988.

McClain, E. P., W. G. Pichel, C. C. Walton, Z. Ahmad, and J. Sutton, Multichannel improvements to satellite-derived global sea-surface temperatures, Adv. Space Res., 2(6), 43-47, 1983.

McClain, E. P., W. G. Pichel, and C. C. Walton, Comparative performance of (AVHRR) based multichannel sea surface temperatures, J. Geophys. Res., 90, 1587-1601, 1985.

Muller-Karger, F. E., The Spring 1998 NEGOM Cold Water Event: Remote Sensing Evidence for Upwelling and for Eastward Advection of Missis- 
sippi Water (or: How an Errant LC Anticyclone Took the NEGOM for a Spin), Gulf of Mexico Science, 1, 55-67, 2000.

Muller-Karger, F. E., J. J. Walsh, R. H. Evans, and M. B. Meyers, On the Seasonal Phytoplankton Concentration and Sea Surface Temperature Cycles of the Gulf of Mexico as Determined by Satellites, J. Geophys. Res., 96(C7), 12,645-12,665, 1991.

Reynolds, R. W., and T. M. Smith, Improved Global sea surface temperature analyses using optimum interpolation, J. Clim., 7, 929-948, 1994.

Strong, A. E., and E. P. McClain, Improved ocean surface temperatures from space, Comparisons with drifting buoys, Bull. Am. Meteorol. Soc., 65(2), 138-142, 1984.

Walton, C. C., Nonlinear multichannel algorithms for estimating sea surface temperature with AVHRR satellite data, J. Appl. Meteorol., 27, 115-124, 1988.

Weisberg, R. H., B. D. Black, and H. Yang, Seasonal modulation of the West Florida continental shelf circulation, Geophys. Res. Lett., 23, $2247-$ 2250,1996
Weisberg, R. H., and R. He, Local and deep-ocean contributions to anomalous water properties on the west Florida Continental shelf, J. Geophys. Res, in press, 2003.

Wentz, F. J., C. Gentemann, D. Smith, and D. Chelton, Satellite measurement of sea surface temperature through clouds, Science, 228, 847-850, 2000.

Wentz, F. J., and T. Meissner, AMSR Ocean Algorithm, Algorithm Theoretical Basis Document (ATBD), Version 2, RSS Tech. Proposal 12,1599A-1, EOS Project, Goddard Space Flight Center, National Aeronautics and Space Administration, Greenbelt, MD 20771, 2000.

Wick, G. A., W. J. Emery, and P. Schluessel, A comprehensive comparison between satellite-measured skin and multichannel sea surface temperature, J. Geophys. Res., 97(C4), 5569-5595, 1992.

R. He, R. H. Weisberg, H. Zhang, F. E. Muller-Karger, and R. W. Helber, College of Marine Science, University of South Florida, St. Petersburg, FL 33701, USA. (ruoying@marine.usf.edu) 